\title{
Patterns and Meanings of English Words through Word Formation Processes of Acronyms, Clipping, Compound and Blending Found in Internet-Based Media
}

\author{
Rio Rini Diah Moehkardi \\ Universitas Gadjah Mada \\ Email: riomoehkardi@ugm.ac.id
}

\begin{abstract}
This research aims to explore the word-formation process in English new words found in the internet-based media through acronym, compound, clipping and blending and their meanings. This study applies Plag's (2002) framework of acronym and compound; Jamet's (2009) framework of clipping, and Algeo's framework (1977) in Hosseinzadeh (2014) for blending. Despite the formula established in each respective framework, there could be occurrences of novelty and modification on how words are formed and how meaning developed in the newly formed words. The research shows that well accepted acronyms can become real words by taking lower case and affixation. Some acronyms initialized non-lexical words, used non initial letters, and used letters and numbers that pronounced the same with the words they represent. Compounding also includes numbers as the element member of the compound. The nominal nouns are likely to have metaphorical and idiomatic meanings. Some compounds evolve to new and more specific meaning. The study also finds that back-clipping is the most dominant clipping. In blending, the sub-category clipping of blending, the study finds out that when clipping takes place, the non-head element is back-clipped and the head is fore-clipped.
\end{abstract}

Keywords: acronym, blending, compound, clipping, word-formation process, meaning

\section{INTRODUCTION}

Human beings are creative users of language who borrow words from other languages, redefine meaning of existing words, create new words and re-form words into new words or into new meanings. Naming newly created or invented products, establishment, ideas and many others, often triggers new word formation. Furthermore, the activities, characteristics or nature of those newly-named produce other new derivatives. For example, one of the most popular social media Twitter (a product) even provides The Twitter Glossary as the words and expressions used in this media may have the same spelling, word class or other grammatical categories with those in the conventional English Vocabulary, yet in this social media they may have different meaning. For example: the word to tweet which is not the same with its original meaning, (of a bird) chirp (Hornby, AS, OALD of Current English, 1987: 932) in this community, is "the act of sending a Tweet. Tweets get shown in Twitter timelines or are embedded in websites and blogs". A tweet means any message posted to Twitter which may contain photos, videos, links, and up to 140 character of text. Moreover, it has its adjectival form, tweetable, which is not available in the latter dictionary. (The Twitter Glossary, https://support. twitter.co/articles/ $13920+166337)$. Even this media also creates new words, such as cashtag 
following the word hashtag, symbolized as \#. And from this community appear words, like: tweet seats; tweetstorm, and tweetup following the rule of English compounding yet still leaving a question when the two constituent words are separated and when not separated.

As this internet-based communication also accessible to youngsters, like in their conventional communication that tends to be kept exclusive among the group members they tend to avoid people outside their group by creating words known only to their group members. In their internet communication, too they create words known among themselves. Many of them are abbreviations such as: CMB (call me back) which is an initialism; but they also create acronyms like MYT (meet you there) which will be pronounced spelt most likely as /mit/ and GR8 (great) showing a more creative use of abbreviating rules.

From the above examples, it is evident that new words and new meanings may be derived from the current existing words, yet the meaning undergo some changes or the same meaning yet expressed in different words. The interesting thing is that these changes seem to follow the regular rules of the English word formation processes but some others seem to follow the language user heart's content. Thus, it is interesting to study the regularity or irregularity of how the words are formed and meaning are developed.

This study basically aims at collecting samples of those new words or new meanings found in the internet based media and describes how they are formed and the new meanings are developed. This study employs English wordformation process of which Marchand in Fandrych (2008) defines as "...... that branch of the science of language which studies the patterns on which a language forms new lexical units, i.e. words. Word-formation can only be concerned with composites which are analysable both formally and semantically ... " such as in compound pickpocket of which the origin words pick and pocket are independent morphemes/lexemes. However, he also suggests that word formation may also involve non-morphemic process, such as those in acronymy (btw), blending (motel), clipping $(a d)$. For example, acronym btw (by the way) is retaining the first letters of each origin word and thus clipping not even a morpheme. (Fandrych 2004 in Fandrych 2008). Furthermore, Fandrych (2004:14 in Fandrych 2008) defines non-morphemic word formation as "...any wordformation process that uses at least one element which is not a morpheme; this can be a splinter, a phonaestheme, a part of syllable, an initial letter, a number or a letter used as symbol." Splinter is defined as ".... formally identical to a clipping, but whereas clippings function as full words, splinters do not" (Concise Encyclopedia of Semantics, 2009 http://grammar.about.com/od/rs/g/splinterterm. $\mathrm{htm})$. A phonaestheme is a particular sound or sound sequence that suggests a certain meaning. For example: the words like glimmer, glitter, and glisten, the phonestheme gl- is associated with vision or light Phonestheme can appear in an initial, medial or final position of a word. (http:// grammar.about.com/od/pq/g/Phonestheme.htm)

Although word formation processes can be observed through coinage, borrowing, backformation, conversion, derivation, compounding blending, clipping and acronym. This research focuses on the last four processes. This goes with the sentiment shared by Ayto (1990) and Steinmetz and Kipfer (2006) in Fandrych (2008) stating that the non-morphemic processes of acronym, blending and clipping are as important as the morphemic ones because they earn increasing popularity in the $20^{\text {th }}$ century amid the vast growth of computer use and electronic communication and due to their economic and humorous nature.

Compounding, the only morphemic wordformation process, is included in this research also because of its vast growing potential, especially those found in the internet-based media.

The present study will explore the patterns found in the data collected from the internet-based media, describe the possible new meaning of the words, and discuss the cultural influence of the community where the words are coined or formed.

Internet-based media accessed through personal computer, laptop, tablet, or smart phone have enabled their users to connect and interact to each other easily. When they stumble on the need of new meaning, readily members of the community propose new words. Online dictionaries, websites dedicating themselves on new words, such as http://www.wordspy.com/, www. 
urbandictionary.com, besides the social media themselves provide evidence of the emergence of new English vocabulary. These data sources are very rich with words representing the 4 types of word formation processes. Despite the richness of the data sources, each type of the word-formation process will be represented by 5 to 10 words hopefully enough to respond to the research aims.

\section{A. ACRONYM}

In contrast to initialism that is forming new words from several source words by taking their initial letters but spelled by its individual words, acronyms studied in this research are pronounced as regular words (Plag, 2003:163). Bauer (1983) in Danks (2003:98) explains that acronym is "a word coined by taking the initial letters of the words in a title or phrase and using them as a new word, for example Strategic Arms Limitation Talks gives SALT." Furthermore, Quirk (1985:1581-2) and then confirmed by Adams in Danks (2003:99) point out that acronyms "may include other than initial letters to make them more word-like, for example radar 'radio detecting and ranging,' yet at the same time may also omit some non-lexical words in the source phrase, for example laser 'Light Amplification by the Stimulated Emission of Radiation.'Most of the time surely, acronym includes all the initial letters, such as the phrase 'Situation normal, all fouled up' becomes snafu (a military slang word). Some acronyms can be spelled with capital and or lower case letters. Usually, when the acronyms have been very well accepted as independent words, they are spelled in lower case letters. (Plag, 2002:163). When the acronyms are pronounced as words, they may contain initial letters, non-initial letters, mixture of initial and non-initial letters. They may also be pronounced as a combination of the two, for example IUPAC /aiupek/. The current study uses the term acronyms to include Plag's definition of abbreviations but will only focus on the last two types of acronyms: spelled as words and spelled as initialism and word. The data then can be classified into three subtypes, the initials are pronounced as a word, combined initials and non-initials pronounced as a word, and initials pronounced as a combination of initial and word.

Figure 1

Acronyms containing only initials and pronounced as words

\begin{tabular}{|c|c|c|c|}
\hline No & Acronyms & Meaning & Spelling/pronunciation \\
\hline A.1.1 & MINT & Mexico, Indonesia, Nigeria, Turkey & $\begin{array}{l}\text { Capitalized all the first letters and pronounced as / } \\
\text { mint/ in contrast to BRICS (Brazil, Russia, India, } \\
\text { China, and South Africa }\end{array}$ \\
\hline A.1.2 & RISE & $\begin{array}{l}\text { Resistance, interval, stretching, } \\
\text { endurance }\end{array}$ & Capitalized all the first letters of the tagline words \\
\hline A.1.3 & KISS & Keep it simple stupid & $\begin{array}{l}\text { Pronounced as a word as there is an existing word } \\
\text { with the same spelling but with different meaning }\end{array}$ \\
\hline A.1.4 & DOC & Drug of choice & Pronounced like shortened word "doctor" \\
\hline A.1.5 & CRAFT & Can't remember a $f^{* * * \text { ing thing }}$ & $\begin{array}{l}\text { Capitalized the first letters of each word including } \\
\text { an article a }\end{array}$ \\
\hline A.1.6 & LULAS & Love You Like a Sister & $\begin{array}{l}\text { Capitalized all the initial letters except the word } \\
\text { You; and pronounced as /lules/ }\end{array}$ \\
\hline A. 1.7 & CU46 & See you for $\mathrm{s}^{* *}$ & $\begin{array}{l}\text { Capitalized each component word with a letter or a } \\
\text { number depending how the word is pronounced }\end{array}$ \\
\hline A.1.8 & $\mathrm{F} 2 \mathrm{~F}$ & Face to Face & $\begin{array}{l}\text { A combination of capital letter of the first letters of } \\
\text { word and number pronounced similar to a word }\end{array}$ \\
\hline A.1.9 & SWATification & $\begin{array}{l}\text { The process of becoming SWAT } \\
\text { (Special Weapons and Tactics) }\end{array}$ & $\begin{array}{l}\text { Capitalized all the initial letters of each word; the } \\
\text { acronym is pronounced like a word, similarly when } \\
\text { it undergoes affixation; the acronym is pronounced } \\
\text { as /swot/ the new derivation is /swotifikesyen/ }\end{array}$ \\
\hline A. 1.10 & ICEing & $\begin{array}{l}\text { Internal Combusting Engine-ing } \\
\text { (parking a non-electric vehicle in an } \\
\text { electric-car charging space) }\end{array}$ & $\begin{array}{l}\text { Capitalized all the initial letters of the phrase; when } \\
\text { it undergoes affixation it is pronounced like "Icing" } \\
\text { /aising/ }\end{array}$ \\
\hline
\end{tabular}


Data 1.1 to 1.2 are the most common acronyms of which usually consist of a string of proper names like in datum1 or a string of activities in a gym in datum 2 . The acronym in datum 1 is a name of organization/institute (1.7) consisting of several countries, similar to BRICS (Brazil, Russia, India, China and South Africa), MINT is a group of emerging economy countries. However in the last acronym taken as example, one word (Africa) is not clipped to A, possibly because the acronym BRICS will be easily remembered as it has its homophone 'bricks'. Similar to MINT it will certainly remind hearers to its homonym, that can be associated with money, suitable with the intention of Fidelity Investments, a Boston-based asset management firm and later was popularized by Jim O'Neill who created the term BRIC and later BRICS to refer to the economy of the countries' the acronym represents (https://en.wikipedia.org/wiki/ MINT \%28economics\%29). This indicates that in some way the rule of retaining the initials of the word members is followed but the catchiness of the formed acronyms is also considerably important that another initial letter in the group is excluded. Data 1.3. -1.8 are acronyms used among teenagers when they are online and the expressions are used to avoid from their parents knowing what they do. Most of the acronyms found in this community are more creative. It includes the initials of each word in the phrase or sentence, including the non-lexical ones, such as an article (a) pronoun (it, you) and preposition (of), the use of letters or numbers to represent words with similar pronunciation. As Plag (2002, 163-163) mentions that an acronym can be spelled in capital letter or in lower case, in the data of acronyms found in this source (http:// edition.cnn.com/2014/12/08/living/internetacronyms-every-parent-should-know/) we can only find them in capital letters. The acronyms can come from a phrase "drug of choice" to form "DOC" shortened form of doctor with which it is associated; or a sentence "Keep it simple, stupid" that even includes a disrespect but intimate address term to form a new word "KISS". The homonymous acronyms are intended to mislead unintended hearers or readers. Data 1.6-1.8 include letters or numbers in the acronyms. They use of $\mathrm{C}$ and $\mathrm{U}$ and not $\mathrm{S}$ and $\mathrm{Y}$ to initialize the word See and You respectively; and 2 to replace to. This possibly happens because $U$ as a single letter is pronounced like the word you /u: /, similarly see is pronounced like the pronunciation of $\mathrm{C} / \mathrm{si}: /$. This inconsistency in initializing can be a matter of efficiency and convenience. Data 1.9 and 1.10 found in a more formal source prove that this type of acronym could become a real independent word, as they could undergo affixation. Possibly because acronym SWAT has actually been widely accepted, it can become a verb SWATify added by a verbal suffix -ify and then become an adjective by adding suffix -ic SWATific then finally it becomes a noun SWATification adding a nominal suffix - ation (Plag, 2002:109-122). Similarly ICE, unrelated in meaning to its homonym, could undergo affixation. In this data it gets suffix -ing and become present participle. Both of them retain their capitalized acronym whereas the affixation is in lower case.

Figure 2

Acronyms containing a mixture of initial and non-initial letters

\begin{tabular}{rlll}
\hline No & \multicolumn{1}{c}{ Acronyms } & \multicolumn{1}{c}{ Meaning } & \multicolumn{1}{c}{ Spelling/pronunciation } \\
\hline A.2.1 & COMPASS & Consortium on Media and Policy Studies & Capitalized acronym; pronounced as /kompes/ \\
A.2.2 & SWEDOW & Stuff We Don't Want & Also in lower case; pronounced as /sweedoh/ \\
A.2.3 & MODEM & MODulator DEModulator & Also appear in lower case \\
A.2.4 & AMPHETAMINE & Alpha-MethylPHEneThylAMINE & Also appear in lower case \\
A.2.5 & GESTAPO & GEheime STAatsPOlizei & Also in lower case \\
\hline
\end{tabular}

The above datum 2.1 is an example of an acronym consisting not only the initials of each member words, but also some non-initial letters, even a letter that does not exist in the member words of the phrase. In the case of the above, the second letter $\mathrm{O}$ can be the first letter of on, or possibly it is from the second letter of Consortium, as this kind of clipping is also possible in acronym. For example: in the acronym radar the first two letter in the acronym is the first two letters of the 
first word of the word members (radio detection and ranging). Moreover, the first letter of $\mathrm{S}$ in the acronym is likely the initial of the word Studies but the last $\mathrm{S}$ in the acronym certainly is not an initial but final letter of Studies. Interestingly, the letter A in the acronym does not belong to any word, especially, because there is not any initial nor noninitial letter A after the word P(olicy). Adding an alien letter in an acronym is made possible to make the acronym pronounced as a newly-formed word or as a homonym of an existing one. Seemingly the intention and creativity of the creator of the acronym made this possible.

Datum 2.2 shows that only the first and the last letters of the acronym are initials, whereas the middle letters are combinations of initial and noninitial letters: WE, in which case even a full word, and the DO is the initial and the second letter of

\section{DON'T}

Whereas in datum 2.1 the acronym has its equal homonym in the English vocabulary; the datum 2.2 does not have its equal; therefore, it is regarded as a newly coined word with new meaning, referring to useless donation, a common expression among the international development community. Even it expands into new compounds: swedow aids and swedow award. (https://talesfromethehood. wordpress.com/2010/05/13/the-best-in-swedow/)

In data $2.3-2.5$ there are more non-initial words included in the acronyms which later become more popular new words than their respective original phrases.

In short, this type acronym reveals more irregularities in selecting the non-initial letters to be included in the acronym yet resulted in an acceptable English pronunciation.

Figure 3

Acronyms with combination of spelling out individual letters and a word

\begin{tabular}{|c|c|c|c|}
\hline No & Acronyms & Meaning & Spelling/pronunciation \\
\hline A. 3.1 & BYAM & Between you and me & $\begin{array}{l}\text { Capitalized the first letter of each word including connector } \\
\text { "and" } \\
\text { Pronounced: /bi wai em/ not /bi wai ei em/ }\end{array}$ \\
\hline A. 3.2 & THOT & That hoe over there & $\begin{array}{l}\text { Capitalized the first letter of each word including the } \\
\text { preposition "over" } \\
\text { Possibly pronounced : /tihot/ not } \\
\text { /t eight o ti/ }\end{array}$ \\
\hline A.3.3 & NTIM & Not that it matters & $\begin{array}{l}\text { Capitalized all the first letter } \\
\text { Possibly: /en tim/ not /en ti ai em/ }\end{array}$ \\
\hline A.3.4 & G-SIFI & $\begin{array}{l}\text { Global-systematically } \\
\text { important financial institution }\end{array}$ & $\begin{array}{l}\text { Capitalized all the first letters and possibly pronounced } \\
\text { /ji saifai/ }\end{array}$ \\
\hline A. 3.5 & OATUS & On a totally unrelated subject & $\begin{array}{l}\text { Capitalized all first letters } \\
\text { Possibly: /o ei tus/ }\end{array}$ \\
\hline
\end{tabular}

From the above data, the first part of the acronym, that can be a single letter (can be a vowel, like in 3.5 or a consonant, like in 3.1-3.4) or multi letters (like 3.5 which is 2 vowels), is spelled, whereas the second part is pronounced like a syllable of a word. The interpretation of the acronym pronunciation is determined by the closeness of the pronunciation of the second part of the acronyms, especially those of data $3.1-$ 3.3 to the existing words (3.1-3.2) in the English vocabulary and English name as in 3.3. Datum 3.5 pronunciation of its second part is similar to the last part of some Latin borrowed words in English, usually in medical terminology, like coitus, abortus, interuptus. Datum 3.4 follows the pronunciation of back-clip WIFI or Wi-Fi or wifi, in which case is back-clip of wireless fidelity. However, G-SIFI is a true initial acronym. (http://www.internetslang. com/WIFI-meaning-definition.asp).

\section{B. COMPOUND}

Bauer roughly defines compound as putting two words into a new word. Compound can be written as a simple word ( hairpin) with hyphen (hair-pin) or separate (hair pin) (Bauer, 1983 in Danks, 2003:47). Plag (2002:170-208) argues that compound, or compounding, or compositions may consist of more than two member words, for 
example:university teaching award committee member. Furthermore, she asserts compounding involves binary structures that may repeat to form a new compound. This is called recursivity that one compound or more can be added to an existing compound. She also argues, that actually a compound is not always and only a combination of words like the above, but also including the use of plural noun as the element of the compound, such as systems analyst, but also a combination of roots, for example: biochemistry, of which bio is actually a bound morpheme that behaves like word not affix; thus, biochemistry is a combination of bound and free morphemes. Another type of combination is of syntactic phrase and word, for example: overthe-fence gossip.

Furthermore, the element members of compound can be divided into left-hand and right-hand members, of which the former in most compounds modifies the latter which is also often called as the head, the more important unit in the structure. English compounds always have their head in the right-hand side, then so-called right-hand head rule, Williams 1981:248 in Plag, 2002:173. This means when the head is a count noun the compound will be a noun count (water dispenser); if the head is a verb than the compound will be a verb (skydive); and if the head is adjective the compound will be an adjective (knee-deep).

However, multi sequence of words is not always a compound, it can also be a phrase. The discussion whether multi sequence of words a compound or phrase has been an endless discussion among the linguists. According to Plag, et.al (Language, vol. 84, No. 4, 2008) most English compounds tend to be stressed on the first element, especially to the nominal compounds, it is also called compound stress rule, as stresses on the left hand member of the compound; whereas phrases are stressed on the final element ( nuclear stress rule). For example: bla'ckboard (a compound, meaning a board to write on) versus black bo'ard ( a phrase meaning a board that is black). Furthermore, Giegerich (2004) in Plag (Language, vol. 84 , no. 4,2008 ) suggests that syntactically, complement-head structures like t'ruck driver are compound and usually left-stressed, whereas modifier-head structures like steel bridge are phrases and usually right-stressed. There are some modifier-head structures, though, that are leftstressed, such as o'pera glasses, ta'ble cloth as the result of lexicalization and thus are compound. Yet, there are some compounds that are right-stressed, for example: geologist-astronomer referring to one single person who is astronomer and at the same time a geologist (Plag, 2005:177). This type of rightward stress accompanies several types of meaning relationships : copulative (scholaracti'vist), locative or temporal (a summer 'night) , causative or made of or created by (Shakepeare 'sonnet). Compound with rightward stress is yet regarded as exception to the compound stress rule.

Furthermore, a noun-noun compound usually cannot be inserted by an adjective; whereas nounnoun phrase can : waterbird - water wild* bird in contrast a three-syllable words can be inserted by an adjective-a three-syllable prosodic word (Plag, 2002:204).

In terms of meaning, compound may have non-compositional (idiomatic) meaning (the two elements : the left-hand and right-hand element together form a new meaning); whereas phrase always have compositional meaning (the left-hand element modifies the right hand element). (Alderete, J., Lecture: concatenative and nonconcatenative morphology, http://www.sfu.ca/ alderete/ hands/sfu323_lec03ConcatNonconcat.pdf, dod: 24/10/2015).In terms of its patterns, compounds are divided into nominal compound, adjectival compound, verbal and neo-classic compounds (Plag, 2002:185-203).

The following is the discussion focusing on the compound form and new meaning it creates.

1. Nominal compounds

It may consist of noun, verb, adjective, and possibly preposition as the left-hand member and a noun head; with the noun-noun combination is the most common type. The noun-noun compound is sometimes called endocentric compound, as the semantic head is inside the compound. Whereas, adjective noun compound (for example: loudmouth) and verb- noun compound (for example: cut-throat) their semantic are strikingly deviant, that their meanings are not on the head but outside the compound, that is loudmouth is not a kind of mouth, but a kind of person, cut-throat is a kind of person. This type of compound is called 
exocentric compound. There are also type of compounds whose left and right elements are semantically equally important and thus both are regarded as heads. This type of compound is labelled copulative compound and is usually hyphenated. For example: singer-songwriter, the doctor-patient gap. The former type of copulative compound is also called appositional compound referring to the same entity with two identity, as in the example, a person who is a singer and songwriter. The latter is coordinative compound denoting two entities that stand in a particular relationship with the noun that follows. As in the example the compound means : a gap between doctor and patient. Another type of nominal compound is synthetic compound of which its head or the right hand member noun is derived from verb and whose left member serve as an argument of the verb. Argument means entity to which the relational noun relates, for example brain surgery means surgery on the brain. Some examples of synthetic compound: church-goer (person who goes to church), bookseller (people who sell books), window-cleaning (cleaning window activity), pasta-eating (eating pasta activity).
However, sometimes the argument linking in compound fails. If the first element of the compound is semantically not compatible with its status as argument, an alternative structure is construed. For example: Sunday driver is not someone who drives Sunday, but who drives on Sunday, street seller is not someone who sells street.

When we turn to the adjective-noun nominal compounds, for example: smallpox, easy chair, blue print, we learn that the meaning of these compounds are not compositional (idiomatic); easy chair is a kind of chair, but what kind it is exactly cannot be predicted from the leftelement of the compound. The verb-noun nominal compound consists of few semantically exocentric compounds, such as pickpocket or spoilsport, and also some endocentric verbnoun compound, such as swearword, think tank. Unlike the exocentric, the right-hand member of endocentric verb-noun compound is not an argument of the verb, but acts as a head which is modified by the initial verbal element. Below is the data obtained from various sources classified into nominal compounds.

Figure 4

Nominal compounds

\begin{tabular}{|c|c|c|c|c|}
\hline No & Compounds & Left-hand & Right-hand & meaning \\
\hline B.1.1 & 3-to-1 shuffle & noun & noun & $\begin{array}{l}\text { Showgoer who tricks of swapping one's third row seat for } \\
\text { a front row on right before a show begins }\end{array}$ \\
\hline B.1.2 & Paperbag waist & noun & noun & $\begin{array}{l}\text { A loose, pleated waistline that gives the impression of a } \\
\text { scrunched bag when gathered at the waist }\end{array}$ \\
\hline B.1.3 & Couch-cushion change & noun & noun & A trivial or disappointingly small amount of money \\
\hline B.1.4 & boyfriend & noun & noun & $\begin{array}{l}\text { In fashion context: clothing that could have come from } \\
\text { man friend's closet }\end{array}$ \\
\hline B.1.5 & Fruit salad & noun & noun & A cocktail of mixed prints that are big and bold. \\
\hline B.1.6 & Wrap belt & verb/noun & noun & A long belt ribboned around a clothe or coat \\
\hline B.1.7 & Charge rage & verb & noun & $\begin{array}{l}\text { Anger and frustration caused by lack of available electric } \\
\text { car charging stations; or by having one's electric car } \\
\text { unplugged by a person whose own car needs charging }\end{array}$ \\
\hline B.1.8 & Retarded dragon & adjective & noun & $\begin{array}{l}\text { A person who breaths quickly to cool down for } \\
\text { too hot food he eats }\end{array}$ \\
\hline B.1.9 & Ugly selfie & adjective & noun & $\begin{array}{l}\text { A deliberately unattractive photographic } \\
\text { self-portrait }\end{array}$ \\
\hline B.1.10 & On-trend & preposition & noun & The most stylish way to say something is trendy \\
\hline B.1.11 & Overconnectedness & preposition & noun & $\begin{array}{l}\text { The state or condition of having over-abundance } \\
\text { of existing or potential technologically mediated } \\
\text { connection to other people or to online resources }\end{array}$ \\
\hline
\end{tabular}


Among the nominal compounds, noun-noun compound is the most productive, "...to be representative of compounding more generally in English..." in Jackendoff (no date, p. 1).Yet, the above data show that the left members of the nominal compound are varied, including preposition (B.1.6 and B.1.7). The left and right hand members are combined with or without hyphen or separated by space. The left-hand members of the noun-noun combination in data B.1.1- B.1.3, according to Levi (1978) and Hacken (1994) in Jackendoff (no date) p:2 can further be elaborated in quasi-syntactic way. The noun 3-to-1 is classified as numeral-noun, whereas paperbag is adjective noun, and couchcushion is classified as paired argument. Datum B.1.1 3-to-1 shuffle is an example of common endocentric noun-noun compound whose semantic head is inside the compound, the shuffle of 3-to-1. Datum B.1.5. at first sight is another endocentric as it may mean the salad of fruit, yet this compound has undergone semantic change into more idiomatic meaning. The compound fruit-salad in this fashion context means "big and bold mixed prints".Although data B.1.2 to B.1.4 are also endocentric compounds as their semantic heads are inside the compound, paperbag waist is a kind of waist but it bears metaphorical meaning as the waist is compared to a scrunched paperbag. Similarly the couchcushion change, the semantic head "change" means a kind of amount of money but the lefthand element of the compound that modifies : couch-cushion is also idiomatic expression to characterize negatively the amount of money. Like fruit salad in the above discussion, boyfriend B.1.4 also semantically evolves into a new meaning. The following example explain the new meaning of boyfriend "I still can't believe P-Middy got papped in a boyfriend shirt." The meaning is a lot more reduced from the literal and more idiomatic previous meaning of "boyfriend": a young male friend and a special male friend/male lover, respectively; whereas this new compound means "piece of clothing that wouldn't look out of place in a man's wardrobe."

The verb-noun nominal compounds B.1.6 wrap belt is endocentric whereas B.1. 7 charge rage is exocentric. Belt as the head word is modified by the left-hand element verb: belt that is wrapped like ribbon, whereas rage is an argument of the verb charge: rage occurs due to the inability to charge. Data B.1.8 and B.1.9 are adjective-noun nominal compounds. Whereas retarded dragon is exocentric and whose meaning is non-compositional (idiomatic), ugly selfie is endocentric and compositional. The semantic of the right-hand element of retarded dragon is not on the head, but a person who is like a dragon, therefore this compound is also an example of metaphorical noun compound "that is based upon the understanding of human and human characteristics through animal and animal characteristics" Benczes (2006, p:93). It is a comparison of a person to a mystical animal, dragon, whose fire unfortunately can not burn down objects rather it cools down something; in other words, a person with this attribute tries to cool down the heat due to hot food by breathing quickly like how a dragon shoots its fire. There are also compounds using preposition, B.1.6 on-trend B.1.7 overconnectedness as its left member whose individual meaning gives emphasis to the meaning of the right-hand member. Both are endocentric whose semantic lie on their heads; thus preposition on reflect the activeness of the trend whereas the preposition over indicating the abundance of being connected to both offline and online resources.

2. Adjective Compounds

Basically, the principles of adjective compounds follow those of the noun-noun compounds, that the non-head element can serve either as modifier or as an argument of the head, for example: knee-deep, sugarfree, respectively. The interpretation adjective compound can be various, such as involving comparison, such as lean as a dog in dog lean; or assuming intensifier, very tired in dog tired; or in syntactic construction the argument would appear next to preposition, for example: free of sugar in sugar-free, dependent on structure in structure dependent. In adjective compounds there are also types similar to those in nounnoun compound, such as copulative compound, appositional such as bitter sweet, sweet sour; 
coordinative compounds used attributively such as a French-German cooperation, a public-private partnership, and also, synthetic compounds, such as: blue eyed, universitycontrolled, hair-raising. Whereas, blue-eyed could be paraphrased as "having X", university controlled receives passive interpretation, controlled by university, the non head expresses the agent argument of the verb, and in hairraising, the non head is usually interpreted as the object of the verbal base of the head. (Plag, 2002:194-196)

The following is the discussion of the data found and categorized as adjectival compounds. may also satisfy the argument position of the adjective head. Thus, the syntactic construction of compound fact-resistant shows that this argument will appear next to preposition, thus resistant to fact. However, as datum B.2.5 has a participle, also called derived adjective, as head, it behaves like verbal synthetic compound (Plag, 2002:195). Therefore swag-swiped means the swag (goodies) is/are swiped. The first element of B.2.6 almost alcoholic and B.2.7 under happy are adverbs that qualify the heads: not really alcoholic and not so happy. Although datum B.2.8. homeless deterrent is adjective-adjective compound, the right-hand

Figure 5

Adjectival compounds

\begin{tabular}{|c|c|c|c|c|}
\hline No & Compounds & Left-hand & Right-hand & Meaning \\
\hline B.2.1. & Granny-chic & noun & adjective & $\begin{array}{l}\text { Fashion inspired by one's grandmother's style; traditional } \\
\text { yet chic }\end{array}$ \\
\hline B.2.2 & School poor & noun & adjective & $\begin{array}{l}\text { Having little ready cash due to the cost of sending one's } \\
\text { children to expensive school }\end{array}$ \\
\hline B.2.3. & Fact-resistant & noun & adjective & $\begin{array}{l}\text { Impervious to reason, counter examples or data especially } \\
\text { when they contradict one's opinion or values }\end{array}$ \\
\hline B.2.4 & Swag-swiped & noun & past-participle & $\begin{array}{l}\text { Another showgoer snatches your goodies when you aren't } \\
\text { looking } \\
\text { e.g.: "Not so much fun, is when you get swag swiped" }\end{array}$ \\
\hline B.2.5 & Hashtag-friendly & noun & adjective & $\begin{array}{l}\text { Of a word or phrase short and memorable enough to be } \\
\text { converted into twitter hash tag }\end{array}$ \\
\hline B.2.6. & Almost-alcoholic & adverb & adjective & $\begin{array}{l}\text { symptoms or behaviors associated with alcoholism, but not } \\
\text { fully blown alcoholic }\end{array}$ \\
\hline B.2.7. & Under happy & Adverb & adjective & Not as happy as one ought or would like to be \\
\hline B.2.8. & Homeless- deterrent & adjective & Adjective & $\begin{array}{l}\text { A physical obstacle or design that deter homeless people } \\
\text { from sleeping in a particular area }\end{array}$ \\
\hline B.2.9 & Demi-sexual & prefix & adjective & $\begin{array}{l}\text { Sexually attracted in the context of an emotional or romantic } \\
\text { relationship }\end{array}$ \\
\hline
\end{tabular}

The data show that the left members are not only noun but also adverb and the right member beside true adjectives, there are also past and present participles. Similar to nounnoun compounds, the left-hand element of the adjectival compound can serve as a modifier or argument to the head. The left-hand element of data B.2.1 to B.2.4 are nouns whose semantic interpretation to the head may involve comparison, such as granny-chic meaning chic like a granny (traditional charm), causative effect, such as school poor, becoming poor due to school expenses. The left-hand element element is best analyzed as back-formation or conversion process, as a noun.

3. Verbal compounds

The non-head of the verbal compounds can be a noun (ghost-write), adjective (blindfold), or verb (dry-clean). The majority of verbal compounds is analyzed as the results of backformation or conversion process from noun-noun compounds with either a verbal noun in -ing or a person noun in-er. This type of compound seems to be regular copulative of which integrating two events into one. Below are data of verbal compounds found from various sources. 
Figure 6

Verbal compounds

\begin{tabular}{rllll}
\hline No & Compounds & Left-hand & Right-hand & \multicolumn{1}{c}{ Meaning } \\
\hline B.3.1 & Binge-listen & noun & verb & $\begin{array}{l}\text { To indulge in an excess of listening to music, } \\
\text { podcasts or other audio contents }\end{array}$ \\
B.3.2. & downbrag & preposition & verb & $\begin{array}{l}\text { To brag less than usual } \\
\text { B.3.3 }\end{array}$ \\
Binge-read & noun & verb & $\begin{array}{l}\text { To indulge in an access of reading especially on the } \\
\text { books of particular authors }\end{array}$ \\
\hline
\end{tabular}

Both B.3.1.and B.3.4 left-hand elements can be explained as a result of a back-formation from noun-noun compound with a verbal noun in ing in head position (binge listening/reading). Like the function of preposition in other type of compound, preposition in verbal compound (down) B.3.3. downbrag also gives quality to the verb head, of becoming less than usual.

4. Neoclassical compounds

They consist of lexemes of Greek or Latin origins combined to form new combinations that are not existed in the original language. These forms are regarded as compounds and not the results of affixation. The position and combinatorial properties, phonological properties, and the status and behavior medial-o often appear in these forms make this compound different from the other types of compounds.
B.4.1-4 are combination of Latin/Greek and English free morpheme, both elements of B.4.5 are non-English: Greek.

\section{CLIPPING}

Clipping is also known as "truncation" adopting a morphological approach (Jamet in Lexis Special: Lexicology \& Phonology, 2009) and sometimes is interchangeably called as "splinter" in Danks (2003:35). Bauer (1986:233) in Danks (2003:35) explains the phenomenon of clipping as "the process whereby a lexeme (simplex or complex) is shortened, while still retaining the same meaning and still being a member of the same class form." Furthermore, Bauer (1994:40) in Jamet (Lexis Special: Lexicology \& Phonology, 2009) adds that "...clipping frequently does change the stylistic value of the word," usually

Figure 7

Neoclassical compounds

\begin{tabular}{|c|c|c|c|c|}
\hline No & Compounds & Left-hand & Right-hand & Meaning \\
\hline B.4.1 & hyperpalatable & prefix & adjective & $\begin{array}{l}\text { Extremely tasty, even addictively, particularly due to } \\
\text { a mixture of fat, salt, and sugar }\end{array}$ \\
\hline B.4.2 & Auto-buy & prefix & verb & $\begin{array}{l}\text { To automatically purchase the next version or } \\
\text { edition of something because you have liked the } \\
\text { previous items in the series }\end{array}$ \\
\hline B.4.3 & Otherhood & pronoun & suffix/noun & $\begin{array}{l}\text { The state of being a woman who is not a mother, } \\
\text { women who are not mothers collectively }\end{array}$ \\
\hline B.4.4 & heutagogy & noun/Gr & suffix/noun & The study of self-determined learning \\
\hline B.4.5 & pedophile & noun & suffix/noun & $\begin{array}{l}\text { individuals with a primary or exclusive sexual } \\
\text { interest in prepubescent children aged } 13 \text { or younger }\end{array}$ \\
\hline
\end{tabular}

From the table, the position of the Latin/ Greek affixes can be in the left or the right of the compound followed or proceeded by free morphemes: hyper- ; auto- and -hood; -agogy; -phile respectively. Interestingly the word class and the meaning of the compounds are determined by the free morphemes. Whereas becomes less formal, but not the meaning nor the part of speech.

Once a word is clipped, it becomes autonomous and can be combined with other word-formation processes. For example, (in How I met Your Mother, sitcom, Ep. 8 I in Jamet, ibid:18): brother - is clipped to bro, then it can be combined 
to become: broccasion, bro-choice rally, brotime. The clipped word can adopt all the properties of the full form: noun - bros (plural); adjective broing away party; verb - don't bro me.... Bassac (2004:171 in Jamet, ibid:20) mentions the semantic restrictions that the clipped forms need to be long enough to mean something. Although, the clipped forms do not generate new meaning, they carry different connotation or undergo narrowing meaning. Morphologically, the formation of the new clipped is hard to predict. The deleted parts are often not morphs in any sense.

Jamet (ibid, p. 17) finds that syntactically there are noun, adjective, verb, and rarely adverb clips. However, most clips are nouns. Even adjectival clipped forms are often converted into nouns. For example: traditional-trad; bisexual - bi.

The patterns of clipping are: a. back-clipping (apocopation), for example: binos (binoculars); b. fore-clipping (apheresis), for example: loid (celluloid); c. both initial and final part of the word (syncope), for example: pajamas - jam; refrigerator - fridge; d. median clipping, the middle of the word is dropped: parachute trooper - paratrooper. As there is some overlap between clipping and blending, this research will also consider the clipping of both halves of a compound as clipping and as long as there is no overlapping between the compounding words. As in the data median clipping are not found this category will not be discussed. The following data, taken from various internet sources, are categorized into the above-mentioned clipping patterns. It is clear that back-clipping is the most dominant clipping compared to other types of clipping. It is proven that even Wikipedia does not provide the list of English apheresis (fore-clipping) nor syncope (initial and final clipping), whereas there is a list of apocopations.

Figure 8

Back-clipping (apocopation)

\begin{tabular}{|c|c|c|c|}
\hline No & Clipped form & Original word(s) & Source of usage/ notes \\
\hline C.1.1 & ganj & ganja & $\begin{array}{l}\text { "Turns out a day in the life of the ex-Beatle, whose band famously smoked } \\
\text { ganj with Bob Dylan in } 1964 \text { when it was edgy to do so, so no longer } \\
\text { involves a toke." (Other terms relating to 'toke': toke fest; Definitions } \\
\text { include: get high, smoke marijuana in a group of eight or more people } \\
\text { while passing four marijuana cigarettes: onlineslangdictionary.com) }\end{array}$ \\
\hline C.1.2 & ridic & ridiculous & "The new words include popular slang like "ridic" (short for ridiculous), \\
\hline C.1.3 & pec & pectoral & $\begin{array}{l}\text { "Pec implants look and feel remarkably natural and have helped many } \\
\text { men feel more self-confident and masculine." }\end{array}$ \\
\hline C.1.4 & guac & guacamole & \\
\hline C.1.5. & Preggo/preggy & pregnant & Additional suffix + go/gy to the clipped form \\
\hline C.1.6. & Lipo* & liposuction & Shortened neoclassic compound \\
\hline C.1.7. & Pedo* & pedophile & Shortened neoclassic compound \\
\hline
\end{tabular}

As Bauer (1994:40) in Jamet (2009:21) suggests "the formation of new clipped forms is hard to predict" as the clipped form are not clearly morph. This phenomena can also be seen in data C.1.1 ganj that is clipped its final letter -a and -ulous that is not a morpheme from ridiculous (C.1.2) and -amole from guacamole (C.1.4). However, in data C.1.3. pectoral, the clipped part is a morpheme. Interesting phenomenon occurs in datum C.1.5 the shortened pregnant preggo /preggy, morphologically back-clipped the second syllable -nant; yet the remaining part get an additional vowel /o/ or //i/. This possibly is following what Tournier 1985 (in Jamet, 2009:22) calls "suffixation fantaisiste" accompanying clipping champers (champ clipped from champagne); beano (clipped from bean fest). Data C.1.6 lipo and C.1.7 pedo are examples of clipping neoclassic compounds, liposuction and pedophile, respectively, of which one of the elements, is Greek or Latin pseudo lexeme : liposuction, but in the case of pedophile the compound consists of Greek prefix pedo or paedo- and head philo or phile. Both head words of these neoclassic compounds are clipped. 
Data C.1.8 - C.1.9 are examples of compounds whose one of or both element (s) are back-clipped. In data C.1.8 op-doc whose origin compound opiniated-documentary is hyphenated whereas incel (involuntary celibate), is not separated both its compound and its clipping. Both of them undergo back-clipping. The origin compounds of lad lit (C.1.10) and tech-free (C.1.11) lad literature and technology-free are differently back-clipped. Whereas the former has its head back-clipped, the latter the non-head is clipped. These two clipped forms of lit and tech have been widely used in varied combinations, such as teen lit, chick lit, sick lit (usually hyphenated when they are used as adjective), hi-tech (of which the left element has also been clipped) no-tech tourism.

Figure 9

Fore-clipping (apheresis)

\begin{tabular}{|c|c|c|c|}
\hline No & Clipped form & Original word(s) & Source of usage/ notes \\
\hline C.2.1. & because & $\mathrm{coz}$ & \\
\hline C.2.2. & piku & Pi haiku & A haiku on the theme of the mathematical constan pi \\
\hline
\end{tabular}

Not only is the fore part clipped; the second syllable undergoes reduction. The word piku is another example clipped not separated compound whose left-hand element is actually a mathematical term combined with a Japanese borrowed word haiku, a short form of Japanese poetry ( https:// en.wikipedia.org/wiki/Haiku) the head word is them fore-clipped and left the second syllable combined with the left-hand of the compound.

Figure 10

Initial and final part (syncope)

\begin{tabular}{rrrl}
\hline No & Clipped form & Original word(s) & \multicolumn{1}{c}{ Source of usage/ notes } \\
\hline C.3.1 & Pup nup & Puppy prenuptial & $\begin{array}{l}\text { A prenuptial agreement that specifies who gets custody of } \\
\text { the couple's dog or dogs }\end{array}$ \\
\hline
\end{tabular}

Pup nup is originally a compound puppy prenuptial which then undergoes different ways of clipping, whereas the left-hand element undergoes back-clipping, the head undergoes initial clipping.

\section{BLENDING}

Yule, 2006:53-9 in Hosseinzadeh, 2014, International Journal of English and Linguistic Research, vol. 2, No. 2, pp.15-26, says that similar to compounding, blending involves the combination of two separate forms to produce a single new term, yet different from compounding, in blending, one or more of the forms have been shortened. The shortening can be by simple omission of a part of a word or it can be a result of overlapping sounds or letters (Algeo, 1977:47-64 in Hosseinzadeh, ibid:18). In Lewis Carroll's word 'it's like a portmanteau', there are two meanings packed in one word" (Lewis Carroll, 1996:102 in Hosseinzadeh, ibid:18). Based on how blending is formed, Algeo (1977) divides blends into three groups:
1. Phonemic overlap: a syllable or part of a syllable is shared between two words, for example: scanxiety - phoneme /an/ shared by scan and anxiety.

2. Clipping: the shortening of two words and compounding them:

2.1. Back-clipping: the beginning of a word is retained, for example: renovation + vacation becomes renovacation.

2.2. Fore-clipping: the final of the word is retained, for example: prom + proposal the second element word is fore-clipped to become promposal.

2.3. Middle clipping (syncope): the middle part is retained, for example: (in)flu(enza).

2.4. Complex clipping: clipped form used in compound; one part of the original compound remains intact, for example: renovacationisanexampleofthiscategory.

3. Phonemic overlap and clipping: shortening of two words to a shared syllable and then compounding: broccasion-bro(ther)ccasion.

The data are categorized into the abovementioned patterns 
Figure 11

Phonemic overlap

\begin{tabular}{clll}
\hline No & \multicolumn{1}{c}{ Blends } & \multicolumn{1}{c}{ Origin words } & \multicolumn{1}{c}{ Meaning } \\
\hline D.1.1 & internest & internet $+n e(s) t$ & $\begin{array}{l}\text { The cocoon of blankets, pillow, and comfy things you gather around } \\
\text { yourself to keep warm whilst spending long amounts of time on the } \\
\text { internet }\end{array}$ \\
D.1.2 & textpectation & $\begin{array}{l}\text { Tex }(t)+\text { expectation } \\
\text { The }(\mathrm{u}) \text { ngry }+ \text { angry }\end{array}$ & $\begin{array}{l}\text { The anticipation one feels when waiting for a response in a text message } \\
\text { Bad-tempered or irritable as a result of hunger }\end{array}$ \\
D.1.3 & hangry & error $+(\mathrm{t})$ errorist & Someone who repeatedly makes mistakes \\
D.1.4 & errorist & fare $+f(\mathrm{o})$ recasting & Predicting when the price of an upcoming flight will be at its lowest \\
D.1.5 & farecasting & You + universe & The entirety of creation that relates to one specific, narcissistic individual \\
D.1.6 & youniverse &
\end{tabular}

From the above data it can be explained that data D.1.1 and D.1.2. have similar pattern that the overlap part (in bold italic) shares one phoneme belong to one member of the compound (italic within bracket). For example the phoneme /s/ of nest is included in the blend.

Unlike the previous two data, data D.1.3 to D.1.5 drop one phoneme belonging to one member of the compound (non-italic within bracket) and not included in the blend. For example the phoneme /t/ in terrorist is dropped in the blend.

Unlike previous datum where "you" is often pronounced as " $u$ " in this datum the spelling is kept as it is and rather the phoneme $/ \mathrm{u} /$ in universe is overlapped to it. It relates to the meaning of the blend that gives emphasis on the "you" as the center of the universe.

Figure 12

Clipping-shortening two words and combine them

\begin{tabular}{|c|c|c|c|}
\hline No & Blends & Origin words/process & Meaning \\
\hline D.2.1 & guncle & G(ay) + uncle & $\begin{array}{l}\text { A term of endearment to a non-related gay male who is regarded } \\
\text { as honorary uncle by his friends and their children }\end{array}$ \\
\hline D.2.2 & hiberdating & Hiber(nation) + dating & $\begin{array}{l}\text { Someone who ignores all their other friends when they are dating } \\
\text { a boy/girlfriend }\end{array}$ \\
\hline D.2.3 & nerdjacking & nerd + (hi)jacking & $\begin{array}{l}\text { In conversation, digressing into extreme and or unnecessary } \\
\text { detail about one's passion }\end{array}$ \\
\hline D. 2.4 & chairdrobe & chair + (war)drobe & $\begin{array}{l}\text { The art of piling clothes on a chair to be used in place of a closet } \\
\text { of dresser }\end{array}$ \\
\hline D.2.5 & unkeyboardinated & $\begin{array}{l}\text { Un(coor)dinated }+ \\
\text { keyboard }\end{array}$ & $\begin{array}{l}\text { Lacking physical or mental keyboard coordination, unable to } \\
\text { type without repeatedly making mistakes }\end{array}$ \\
\hline D.2.6 & nomygod & $\mathrm{N}(\mathrm{o})+\mathrm{o}(\mathrm{h})+$ my god & A strong, negative way of expressing disbelief or surprise \\
\hline D. 2.7 & complisult & Compli(ment) + (in)sult & Backhanded compliment \\
\hline
\end{tabular}

Data D.2.1 and D.2.2 are examples of compound of which one element gay and hibernation are back-clipped and combined with the whole part of the other element, in which case are the heads of the compound. The clipping however is rather different, as gay is a mono syllable the clipping is then non-morphemic, leaving a single phoneme $/ \mathrm{g} /$, whereas the second word, hibernation is back-clipped its last two syllables. The next two data, the heads of the compound, hijacking and wardrobe, are fore-clipped before they are combined with the left-hand words. Again the clipping are not the same. Whereas hijacking is clipped syllabically, wardrobe is not. It seems when the head is clipped this must be fore-clipping; whereas when the left-hand word are clipped then it should be back-clipped. Here more example of blends with fore-clipped heads: cellfish (cell + selfish); bedgasm (bed + orgasm); whereas the nonheads are back-clipped: transparent (transgender + parent). Datum D.2. 5 is an example of a blend undergoing median-clipping. The left-hand word 
uncoordinated is clipped its center "coor" to be inserted with the second element word keyboard. The last two data show how both elements of the compounds are clipped to become new blends. The clipping is consistent with what happen in the first two and second two data in the above: back-clip the left-hand word and fore-clip the right-hand word.

Figure 13

Phonemic overlap and Clipping:

shortening of two words to a shared syllable and then compounding

\begin{tabular}{|c|c|c|c|}
\hline No & Blends & Origin words & Meaning \\
\hline D.3.1 & grumpa & Grum(py)+ (grand) (pa) & $\begin{array}{l}\text { Grumpy grandpa who always insists that the world was better } \\
\text { when he was a kid }\end{array}$ \\
\hline D.3.2. & destinesia & Desti(nation) $+($ am)(nesia $)$ & $\begin{array}{l}\text { A condition you are suffering from when you set out } \\
\text { somewhere to do something, only to find that when get there } \\
\text { you have forgotten what you were going for }\end{array}$ \\
\hline D.3.4 & shaleionaire & Sha(1)(e) $+($ mil $)(1)$ ionaire & $\begin{array}{l}\text { A person who owns lands that sit over a shale deposit and has } \\
\text { become rich by leasing that land to a company that extract } \\
\text { natural gas from the shale }\end{array}$ \\
\hline D.3.3 & niephlings & $(\mathrm{Nie})(\mathrm{ce})+(\mathrm{ne}) \mathrm{ph}(\mathrm{ew})+(\mathrm{sib}) \operatorname{lings}$ & A person's niece and nephew \\
\hline
\end{tabular}

This type of blend also follows the convention of clipping in the previous category, the head of the compound is fore-clipped, grand, am and mil are clipped from grandpa, amnesia, and millionaire respectively, and the remaining parts (-pa, - nesia, and 1-) overlap with remaining part of the nonhead that have been back-clipped: grum- and desti- In the case of millionaire, after being foreclipped (mil) and $/ 1 /$ is overlapped, the rest then is combined to the blend.Datum D.3.3. is a three word compound, the first two non-heads are backclipped and overlapped (nie + ne ) and combined with the remaining part of the second non-head / $\mathrm{ph} /$ and the remaining part of the head that has been fore-clipped (-lings)

\section{CONCLUSION}

This research finds out that data collected are formed in accordance with the word formation of acronym, compound, clipping, and blending, laid out in the respective theory. However, there are some notes to be taken into account. The data analysis of acronyms do not find acronyms spelled in lower case; this can be understandable, as the data are newly formed words. Time will tell whether they become widely accepted words then they will be spelled out in lower case and also undergo derivation process, like SWATification whose capitalization is retained possibly for certain purpose. The Many acronyms are spelled and pronounced following existing patterns: WIFI $\rightarrow$ SIFI, MIFI; OPEC $\rightarrow$ APEC $\rightarrow$ AIPEC. There is some flexibility in spelling and pronouncing words. Some words may be spelled like the pronunciation of some letters (you -- /u/; see - c; newbie -- NOOB) or the pronunciation of number, for example: CU46

In the data analysis of compounding, numbers can also be used as the element of compound: 3-to-1 shuffle. There are also compounds that have been in the English vocabulary: boyfriend and fruit salad, however, at the present study they have new and more specific meaning. Nominal compounds are likely to have metaphorical and non-compositional meanings.

This study also confirms that the length of the clipped part is unpredictable. There is also evidence in the data that a clipped word may obtain "suffixation fantaisiste" Many clipped words have become well-accepted but almost always in combination with other clipped or full words, such lit $\rightarrow$ teen lit, chick lit, sick lit; tech $\rightarrow$ hi tech, comtech.

Further and more focused study with bigger data is needed to confirm and give support to the findings mentioned above.

\section{BIBILIOGRAPHY}

Alderete, J. (2015). "Lecture note: concatenative and non-concatenative morphology". (http://www.sfu.ca.alderete/hands/ 
sfu/323_lec03ConcatNonconcat.pdf,dod: $24 / 10 / 2015)$

Benczes, Reka. (2006). Creative Compounding in English.JohnBenjaminPublishingCompany

Carstairs-McCarthy, A. (2002). An Introduction to English Morphology: Words and their Structures. Edinburgh University Press

Danks, Debbie. (2003). Separating Blends: a Formal Investigation of the Blending Process in English and Its Relationship to Associated Word Formation Processes. University of Liverpool

Fandrych, Ingrid. (2008) "Submorphemic elements in the formation of acronyms, blends and clippings", Lexis 2: $105-123$.

Giegerich, Heinz J. no date "Compounding and Lexicalism" in Rochelle Lieber and Pavol Stekauer (eds)., Handbook of Compounding. Oxford University Press

Hornby, A.S. (1987) Oxford Advanced Learner's Dictionary of Current English. Oxford University Press

Hosseinzadeh, N. M. (2014). "New blends in English Language". International Journal of English Language and Linguistics Research, vol.2, No.. 2: $15-26$

Jackendoff, R. 2010. The Ecology of English NounNoun Compound, chapter 13 in "Meaning and the Lexicon: the Parallel Architecture 1975 2010", Oxford University Press,

Jamet, D. (2009). "A morphological approach to clipping in English. Can the study of clipping be formalized?" in Lexis Special: Lexicology \& Phonology: 15-31

Kemmer, R. (2015). "Types of word formation processes" (Ling/Engl 215 course information). http:// www.ruf.rice.edu/kemmer/words/wordtypes. html dod: 16.10.2015

Plag, Ingo. (2002). Word-formation in English. Cambridge University Press
Plag, I., Kunter, G., Lappe, S., and Braun, M. (2008) "The role of semantic, argument structure, and lexicalization in compound stress assignment in English" in Language,vol. 184, no. 4 : 760-794

Quirk, R., Greenbaum, S., Leech, G. and Svartvik, J. .(1985). A Comprehensive Grammar of English Grammar, Longman.

Weiskopf, D.A. (2007). "Compound nominal, context, and compositionality" in Synthese, 157: 161 $-204$

Yousefi, M. (2014). Word Formation Processes in English. Unpublished paper.

\section{INTERNET SOURCES:}

Word formation processes, www.kau.edu.sa/ files/0006268/files/8714_5word\%20 formation \% process.pdf

The Twitter Glossary, https://support.twitter.co/ articles/13920 + 166337

https://en.wikipedia.org/wiki/MINT \%28economics $\% 29)$

http://www.internetslang.com/WIFI-meaningdefinition.asp)

\section{DATA SOURCES:}

www.oxforddictionaries.com

www.urbandictionary.com

www.wordspy.com

www.guardian.com

www.brighthubeducation.com

edition.cnn.com2014/12/08/living/internet-acronymevery-parent-should-know

en.wikipedia.ord./wiki/acronym

www.internetslang.com 